\title{
Article \\ A Qualitative Analysis of Burn Injury Patient and Caregiver Experiences in Kwazulu-Natal, South Africa: Enduring the Transition to a Post-Burn Life
}

\author{
Camerin A. Rencken ${ }^{1, *(\mathbb{D}}$, Abigail D. Harrison ${ }^{2}$, Adam R. Aluisio ${ }^{3}$ and Nikki Allorto ${ }^{4,5}$ \\ 1 Brown University School of Public Health, Providence, RI 02912, USA \\ 2 Department of Behavioral and Social Sciences/International Health Institute, \\ Brown University School of Public Health, Providence, RI 02912, USA; abigail_harrison@brown.edu \\ 3 Department of Emergency Medicine, Warren Alpert School of Medicine, Providence, RI 02912, USA; \\ adam_aluisio@brown.edu \\ 4 Department of Surgery, University of KwaZulu-Natal, Durban 4041, South Africa; nikkiallorto@gmail.com \\ 5 Pietermaritzburg Metropolitan Burn Service, Pietermaritzburg 3201, South Africa \\ * Correspondence: camerin_rencken@alumni.brown.edu
}

\section{check for}

updates

Citation: Rencken, C.A.; Harrison, A.D.; Aluisio, A.R.; Allorto, N. A Qualitative Analysis of Burn Injury Patient and Caregiver Experiences in Kwazulu-Natal, South Africa: Enduring the Transition to a Post-Burn Life. Eur. Burn J. 2021, 2, 75-87. https://doi.org/10.3390/ ebj2030007

Academic Editors: Naiem Moiemen and Peter M. Vogt

Received: 30 April 2021

Accepted: 24 June 2021

Published: 1 July 2021

Publisher's Note: MDPI stays neutral with regard to jurisdictional claims in published maps and institutional affiliations.

Copyright: (C) 2021 by the authors. Licensee MDPI, Basel, Switzerland. This article is an open access article distributed under the terms and conditions of the Creative Commons Attribution (CC BY) license (https:/ / creativecommons.org/licenses/by/ $4.0 /)$.

\begin{abstract}
Over 95\% of fire-related burns occur in low- and middle-income countries (LMICs), an important and frequently overlooked global health disparity, yet research is limited from LMICs on how survivors and their caregivers recover and successfully return to their pre-burn lives. This study examines the lived experiences of burn patients and caregivers, the most challenging aspects of their recoveries, and factors that have assisted in recovery. This qualitative study was conducted in KwaZulu-Natal, South Africa at a 900-bed district hospital. Participants $(n=35)$ included burn patients $(n=13)$ and caregivers $(n=22)$ after discharge. In-depth interviews addressed the recovery process after a burn injury. Data were coded using NVivo 12. Analysis revealed three major thematic categories. Coded data were triangulated to analyze caregiver and patient perspectives jointly. The participants' lived experiences fell into three main categories: (1) psychological impacts of the burn, (2) enduring the transition into daily life, and (3) reflections on difficulties survivors face in returning for aftercare. The most notable discussions regarded stigma, difficulty accepting selfimage, loss of relationships, returning to work, and barriers in receiving long-term aftercare at the hospital outpatient clinic. Patients and caregivers face significant adversities integrating into society. This study highlights areas in which burn survivors may benefit from assistance to inform future interventions and international health policy.
\end{abstract}

Keywords: rehabilitation; burn injury; lived experiences; global health; South Africa

\section{Introduction}

Burn injuries are an important global health concern, with estimates that over 95\% of burns occur in low- and middle-income countries (LMICs) [1]. This represents an important and often overlooked global health disparity, as the gap in burn-related mortality rates between LMICs and high-income countries is one of the largest for any injury [1]. Globally, burn injuries account for 300,000 deaths each year, and millions experience chronic disabilities and sequelae [1,2]. When accounting for wound contractures, scars, and other physical impairments, burn injuries result in ten million disability adjusted life years (DALYs) globally each year [1]. However, that statistic does not account for sequelae such as stigma, social isolation, and difficulty integrating into society, which often create significant psychological impacts [1]. With recognition of the long-term effects of a burn injury, such as the psychological morbidity for both the patient and community, public health research focuses is shifting towards the chronic impact and need for research on the psychosocial impact of scars [3-5]. 
A burn injury is an often unexpected traumatic event, which can result in significant effects to the survivor, their family, and community [6]. It is widely accepted that burn injuries can cause severe psychological and physical impediments, but further research is needed to identify ways in which burn injury survivors and their loved ones successfully return to their pre-burn lives [2]. Common secondary pathologies from burn injuries include post-traumatic stress disorder, depression, social stigma and rejection, and difficulties accepting self-image [7,8]. Additionally, patients have to overcome physical barriers including obtaining functional mobility, and returning to work or school $[9,10]$. Mental health challenges have been reported in patients sustaining both severe and non-severe burn injuries alike [3,11]. Studies conducted in the United States have identified that a patient's ability to readjust to daily life postburn is not completely conditional on the physical components of the burn itself, but rather on family and societal support, coping techniques, and psychological well-being of the survivor [12,13]. Similar research is needed in less-resourced settings to increase survivor outcomes where the burden of burns is high.

Qualitative data exploring the post-discharge experience and society integration for patients and caregivers is extremely scarce in Sub-Saharan Africa, where burns are notably apparent [1,14-17]. Recent literature has highlighted the importance of qualitative research in burn care due to its ability to capture the perspectives and lived experiences of those involved and its potential for improving burn care, patient outcomes, and influencing policy [18]. Each year, over 3\% of the population is burned, and the majority of survivors experience significant complications [19]. To support the high incidence of burn injuries and support survivors, programs need to address the psychological, physical, and psychosocial needs of this specific population. However, the lack of resources allocated to burn injuries only exacerbates the burden placed onto health care facilities, staff, patients, and the community [19]. Burn injuries in LMICs often have drastic outcomes, such as social isolation, family abandonment, unemployment, and falling deeper into poverty [1,12]. The objective of this study is to examine detailed lived experiences of both the most challenging aspects of recovery, as well as highlight factors that have assisted survivors in achieving their best outcomes. This study aims to understand how burn injury survivors and their caregivers adjust to and cope with daily life after being discharged from a hospital in the specific setting of KwaZulu-Natal (KZN), South Africa.

\section{Materials and Methods}

\subsection{Setting}

This study was conducted in Pietermaritzburg, KZN, South Africa at Edendale Hospital; a 900-bed regional public hospital serving a population of 3 million patients. The burn service at Edendale Hospital averages 28 admissions per month [20]. The average TBSA (percentage of total body surface area affected by the burn; one indicator of burn severity) for adults and children was $9 \%$ and $13 \%$, respectively [20].

\subsection{Recruitment}

Purposive sampling was employed. Participants were screened and recruited for the interviews either in person at the outpatient clinic or via flyers posted in the hospital or over the phone from June 2019 until August 2019. Interested patients spoke to study personnel, fluent in English and isiZulu, who explained the purpose and procedures of the study, and proceeded to seek informed consent. The final sample size was based on saturation analysis determined by ongoing coding conducted during data collection.

\subsection{Participants}

The study participants were comprised of (1) adult burn injury patients and (2) caregivers of burn injury patients. For the purposes of this study, the burn patients linked to the caregivers are referred to as caregiver kin. The caregiver kin are referenced frequently in the caregivers' accounts of caring for a burn injury patient. Individuals were excluded if unable to give informed consent. Interviewed patients met the following criteria: (1) age 
18 years or older; and (2) experienced a burn injury within the past three years. The interviewed parents or primary caregivers of burn patients met the following inclusion criteria: (1) age 18 years or older; (2) parent or primary caregiver to child/adolescent 0-17 years of age who experienced a burn within 3 years. In two cases, study staff included caregiver kin aged 26 and 53. This reflects that adult burn injury patients, not exclusively children, may rely on family support and lead to disruptions in family members' lives during the recovery process.

\subsection{Data Collection}

Interviews were conducted for approximately thirty minutes, using a semi-structured interview guide organized by a priori domains, guided by a literature search, clinical relevance for this specific contextual setting, and consultation with two qualitative methods experts, two burn care professionals, and one survivor (Appendices A and B). These domains were: (1) initial burn incident, (2) participation in aftercare, (3) current psychological health, (4) changes in post-discharge behavior, (5) returning to work/school and (6) coping. Questions were written to be open-ended to provide an opportunity for the participant to speak freely regarding their experience. Interviews were conducted in the participant's language preference, which resulted in 34 isiZulu interviews and one English interview. Participants were reimbursed for their time and transportation. Demographic and clinical data were collected from patient charts. These data included TBSA, age, sex, and whether or not the burn survivor returned for aftercare. The hospital holds an outpatient clinic for recovering survivors weekly to receive rehabilitation and burn aftercare. Patients are advised to come, at minimum, to the initial wound appointment and until wound healing is complete.

\subsection{Data Analysis}

To ensure rigor during qualitative analysis, investigators selected the design through careful consideration of different possibilities for methodological approaches to qualitative data analysis. The analytical approach included use of multiple perspectives to evaluate both the data (e.g., joint reading of transcripts prior to coding) and the process of coding (codebook development; review of coded data). Interviews were transcribed verbatim and uploaded into NVivo12 software (QSR International Pty Ltd., Version 12, 2018) [21]. The codebook framework was applied iteratively with new codes added as they emerged. Data were analyzed using thematic analysis [22,23]. Thematic analysis was initially conducted by one co-author (CR) and refined by co-authors (CR, $\mathrm{AH}$, and NA). Results were then organized thematically to understand the relationships between the domains and how they relate to a burn survivor's ability to return to their life pre-burn injury. Descriptive statistics are presented as the mean.

\section{Results}

\subsection{Overview of Results}

This study included thirty-five participants in total $(n=13$ patients and $n=22$ caregivers). The thirteen adult burn patients included seven males and six females with an average age of 32.8 years (Table 1). Caregivers were included in the study in order to report on the post-burn experiences of the burn survivors in their care, who were mainly children $(n=20)$, but also included two adults who are included in the category of 'caregiver kin'.

Although individual caregiver age was not reported, all caregivers were females between the ages of 21-35. Demographic characteristics of the caregiver kin patients and adult patients are presented in Table 1. Amongst the burn patients, 25 followed up for the initial appointment post-discharge, and $10 \mathrm{did}$ not (Table 1). Caregivers $(\mathrm{n}=22)$ were recruited into the study to report on the experiences of the burn survivors in their care, as well as their own experiences of caring for a burn survivor. This table includes (1) adult burn survivors who were recruited to the study and reported on their own experiences 
with burn injury and recovery, and (2) the caregiver kin burn survivors were reported on by their caregivers.

Table 1. Patient demographics $(n=35)$.

\begin{tabular}{ccc}
\hline & Adult Burn Survivors $(\mathbf{n}=\mathbf{1 3})$ & $\begin{array}{c}\text { Caregiver Kin Burn } \\
\text { Survivors }(\mathbf{n}=\mathbf{2 2})\end{array}$ \\
\hline Aftercare Follow Up & 13 & \\
\hline Yes & 0 & 12 \\
No & & 10 \\
\hline Age (years) & 32.8 & \\
\hline Mean & $21.9-62.0$ & 6.7 \\
Range & & $1.0-53.0$ \\
\hline Sex & 7 & \\
\hline Male & 6 & 8 \\
Female & & \\
\hline TBSA (percentage) ${ }^{1}$ & 11.8 & 10.1 \\
\hline Mean & $0.3-30.0$ & $1.0-35.0$ \\
Range & &
\end{tabular}

${ }^{1}$ TBSA = total body surface area burned.

Patient and caregiver experiences following a burn injury fell into three categories: (1) psychological impacts of the burn, (2) enduring the transition into daily life, and (3) reflections on difficulties survivors face in returning for aftercare.

3.2. Theme 1-The Burn Injury Impacts the Psychological Health of Both the Survivor and Caregiver 3.2.1. Loss of Relationships

Participants had difficulties maintaining pre-injury relationships and struggled to develop new ones. The majority of adult patients reported instances where their friends abandoned them:

"They changed, some of them stopped visiting me. Stopped talking to me. Some they do but...not like before. There is no proper conversation. They are trying to distance themselves." (Participant 13-Patient, Male)

After the burn, survivors often felt they had lost the ability to connect with friends, who could not relate to their traumatic experience: "My friends disappeared." (Participant 2-Patient, Male) Additionally, many experienced challenges with developing romantic relationships.

"Even to start a relationship... the guy was asking me out, he was walking behind me ... I turned back and looked at him, he said "Oh no sorry I thought you were someone else." But I know he saw me. When he was looking at the back, he didn't see the scar but when he looked at me in the front ... that killed me." (Participant 8-Patient, Female)

Caregivers had similar experiences. Many worried they would be judged for being a negligent parent.

"The people are saying that it is my fault that my baby got burned like I don't care about my baby. They say, "how can the baby get burnt" and it was not my fault. I didn't plan for my baby to get burnt." (Participant 7-Caregiver, Female)

During this traumatic time, caregivers face pressure and need the support of their social network. Isolating themselves due to stigma and losing that crucial support further exacerbates the burden placed on the caregiver. Participants reported that transitioning into a life that was once filled with strong personal connections into one where they lack human relationships resulted in feeling alone and without support. 


\subsubsection{Feelings of Isolation}

Patients often felt they had no one to speak to in times of need.

"When I was in hospital the only thing I was thinking was if God can give me one chance to tell people about what I am going through then I will be happy ... I used to take a pen and write on the paper, but I feel like it's pointless ... who will read it." (Participant 8-Patient, Female)

Many patients perceived themselves as a burden to others physically and psychologically. For one patient, the burn took away her autonomy to care for herself, affecting her ability to lead an independent adult life.

"I felt like they are tired. I wished to die because this is forever. Maybe I will be a burden to the people, they will have to look after me all the time." (Participant 12-Patient, Female)

Caregivers similarly felt isolated from their community and reported being blamed and judged for having a baby with a burn injury. Some distanced themselves from friends:

"I was afraid to tell my friends; I was afraid that people would judge me and say that I am careless." (Participant 18-Caregiver, Female)

As a result of these attitudes, many caregivers blamed themselves for the incident.

"I blame myself for him being burned. I feel guilty ... I feel like if I were more careful none of this would have happened. Every day, I blame myself." (Participant 23-Caregiver, Female)

The constant burden of guilt negatively affects the mental health of these caregivers.

\subsubsection{Difficulties Accepting Adjusted Self-Image}

The majority of patients and caregivers expressed concern regarding the change in appearance from the burn. One participant summarized these feelings, saying "when I see my pictures before I got burned, I was crying" (Participant 12-Patient, Female). These negative feelings lowered patients' motivation to return to the daily routine of their pre-burn lives.

"I am staying at home. I am not going out ... I was still scared for my face, for how I look, I always feel negative." (Participant 1-Patient, Female)

The psychological impacts of a burn place immense stress on the entire family. Caregivers corroborated the negative impacts a burn has on one's physical appearance.

"Other kids would laugh at him and say he looks like a baboon and that he has big eyes, and the scar makes him look damaged ... I feel pain when that happens." (Participant 28-Caregiver, Female)

This caregiver described her pain when her child was teased, resulting is psychological trauma for both of them.

"Now he has burn scars and I have to look at those scars every day. I feel useless, there is nothing I can do to take those scars away." (Participant 27Caregiver, Female)

Bullying of a child causes harm for both the child and parent. In the case of burns, many caregivers feel doubly responsible for the injury and its social and physical consequences.

3.3. Theme 2-The Transition into Daily Life Requires Endurance from All Persons Affected by the Burn Injury

Burn survivors often face overwhelming difficulties post-burn with internal recovery and with reintegrating into society due to stigma or physical complications.

"Everything is so difficult now. No one is helping me ... life changed completely."

(Participant 6-Patient, Female) 


\subsubsection{The Impact of Stigma on Societal Reintegration}

For some participants, the challenges to their mental health were more taxing than the physical barriers.

"I think the only part more hurt was my brain or feelings more than the skin. I didn't mind about the skin but inside I was dying." (Participant 18-Patient, Female)

High levels of stigma were reported within the community for the burn patients and caregivers. One participant noted that community members feared even sitting next to a patient with scars.

"Some of them have problems with burn scars. They don't want people with scars to sit next to them." (Participant 7-Caregiver, Female)

In some cases, the community felt pity for those recovering from a burn, which was not received positively by survivors. "They treat me well. But every time they feel sorry for me, and I don't feel comfortable" (Participant 16-Patient, Male). The ability to integrate and feel like a contributing member in one's community post-burn is crucial for working towards a full recovery.

\subsubsection{Returning to Daily Life}

Returning to daily life, including work, is an essential part of recovery, but can be a challenge given the mental and physical changes caused by a burn. These changes may impair everyday activities as well a physical ability to work. "I can't carry heavy things and I can't put my clothes on. Even my arm like this it can't go straight" (Participant 11-Patient, Male). Many patients were unable to continue their old job and had to seek alternative forms of work, as this participant explained:

“Let's say, is a domestic worker. Maybe you wash clothes ... if I use the powder soap, it affects me. Maybe if you are working at a bakery, and you have to face that heat, it's a problem. Maybe if you are working on a farm, it's too hot, when you come back at night you have the blisters and it will affect you. That's why, we are afraid to go work. After you get burnt, our skin is so sensitive." (Participant 12-Patient, Female)

In addition to being physically unable to return to work, many patients faced discrimination during the application process. Some of the patients explained that recovering from the trauma of the burn injury made it impossible to concurrently apply for jobs.

"I stay with my brother. Sometimes she [aunt] sends us money to buy food but sometimes she doesn't. It is hard to survive. When I can't eat, I don't have energy to work because I can't eat well." (Participant 32-Patient, Male)

Caregivers found it hard to return to work. Spending significant amounts of time at their child's bedside was emotionally devastating and resulted in professional setbacks.

"I was going to go look for a job before the baby got burned and I can't go anymore because I have to look after the baby." (Participant 14-Caregiver, Female)

Coping with these changes, including loss of friendships and income, while recovering from a traumatic experience places immense stress on individual patients and caregivers.

\subsection{Theme 3-Burn Survivors and Caregivers Reflected on Experiences Returning for Aftercare to Improve Physical Health}

Returning for aftercare, for example to minimize scar formation or attend physical therapy, helps improve patient outcomes. However, participants spoke about overcoming adversities in order to attend aftercare. 


\subsubsection{Barriers to Returning for Aftercare}

An overwhelming majority of patients referenced cost, specifically for transport, as the leading barrier to accessing rehabilitation services. Even participants who followed up noted that money for transportation was extremely difficult, sometimes impossible, to obtain.

"They explained that I mustn't miss the date to come back. But I don't care about the date because I don't have the money to come back to the hospital." (Participant 9-Caregiver, Female)

The majority of burn injury patients were children who need supervision to return to the clinic. This was the main reason for a number of patients who did not follow up.

"She was supposed to come back, but she can't because there is no one to help her to take her back to hospital, because I am looking after my kids ... there is no one to watch the kids if we leave to go to the hospital." (Participant 35Caregiver, Female)

Another reported reason for not returning to the clinic was physical limitations limiting their mobility. Often, patients needed assistance to get from home to clinic.

"If I come here, I have to bring someone, and I have to pay for that person."

(Participant 16-Patient, Male)

\subsubsection{Facilitators in Receiving Aftercare}

Some participants also reflected on ways they felt supported and were able to return for aftercare. These include government grants, understanding the importance of aftercare, and family support. The South African government gives a number of federal grants to qualifying families and individuals for child-care, disabilities, and pension. Some participants used their disability grant to support aftercare:

"I didn't miss any appointments. My mom made sure that I always come. I applied for a disability grant, so it helps me to come here." (Participant 8Patient, Female)

Understanding the importance of rehabilitation care plays a major role in whether or not a patient follows up after discharge.

“It was hard sometimes, not always, because sometimes I don't have enough money for transport. But I understand very well how important it is to come but I understand very well how important it is." (Participant 10—Caregiver, Female)

Caregivers with family support, including monetary assistance and childcare, were also more likely to follow up. A few caregivers noted that their families helped with childcare while they took the day to return to the hospital.

"My family is supporting me and every time I go to hospital they help with money for transport. Even when I am not around, they take care of the baby." (Participant 21-Caregiver, Female)

\section{Discussion}

Burns, along with injuries more broadly, are a growing global health priority, with recent reports highlighting their physical, psychological, and economic costs [2]. There are few qualitative studies of burn injuries in Sub-Saharan Africa that explore the transition to daily life postburn through the personal accounts of patients and caregivers. Although significant advancements have been made in burn care research, burns are increasingly more prevalent in low resource and low socioeconomic settings [24,25]. This study's qualitative results with 35 participants highlight the difficulties faced by patients and caregivers following a burn injury, including loss of friendships and family relationships, feelings of isolation and self-harm, challenges regarding social reintegration, and fear of community rejection. This study aimed to fill a crucial gap in the literature regarding 
the hardship of transitioning into daily life post-burn in Sub-Saharan Africa, offering an understanding of potential targets for public health programs in order to improve physical and mental health outcomes for burn patients.

This qualitative study brings forward the voices of both patients and caregivers in South Africa, highlighting how both groups are affected deeply by the experience of being burned, or caring for a burn patient. All participants in this study reported an inability to go back to work as a result of the burn injury. Injuries, including burns, place a significant economic burden on families due to the cost of treatment, transportation to clinics, and an inability to obtain an income [2]. One study in Ghana found that after an injury, around one fifth of families reported a decline in food consumption as a result of a limited income [26]. Families reported selling household items to offset lost income [26]. Limiting one's ability to work decreases independence, which places further emotional strain on one's recovery process. Researchers found that returning to work was an important factor in adult patients rehabilitation process [27]. Development of social support programs has the potential to assist burn injury patients in returning to work or finding new employment opportunities that meet their physical and psychological capabilities post-burn.

Learning from the narratives and personal stories of these burn patients and caregivers, a social support group is likely an effective intervention to propose. Such groups would address the needs of both patients and caregivers. The importance of group psychological counselling and peer support for burn patients is widely accepted and shown to be effective in increasing confidence and social integration [28-30]. Social and peer support currently play a vital role in burn survivor recovery in HIC, yet these groups are almost non-existent in LMICs [1]. To our knowledge, there are two reports of burn injury psychosocial support groups in SSA, one in Malawi and one in Cape Town [31,32]. Support groups have an immense opportunity to increase the psychological health of not only the burn patients, but also caregivers. As seen in the results of this study, caregivers have a significant responsibility in caring for a burn survivor, which is heightened when they are additionally caring for more than one child at home. In this under-resourced setting, programs to support caregivers need to be implemented commensurate with patient programs. Campaigns to decrease stigma and promote burn awareness may also reduce barriers for burn patients when reintegrating into society.

Rehabilitation and aftercare are vital aspects of burn care [33]. However, the participants in this study noted an inability to return for aftercare, whether due to monetary difficulties or the need for physical assistance during the trip back to the hospital. One study conducted at the same South African hospital found that one-third of the patients never returned for follow up care. [34] Support programs may have a role in filling these gaps. To assist with adherence to aftercare at the hospital, a transportation program could be initiated to aid families in need. Previous studies have employed different transportation strategies including travel reimbursement, offering a shuttle service, and providing taxi passes to assist in aftercare for chronic diseases [35]. Rehabilitation care needs to be readily accessible for burn injury survivors to improve their outcomes and quality of life. This study found that patients and caregivers alike often returned to the clinic when supported by family. If family members could apply for funds or approved time off work to support their loved ones, the outpatient clinic may see increased retention in care and therefore improved outcomes for patients.

This qualitative study has important limitations. First, only patients who were seen for their burn at a hospital, and therefore received medical attention, were included. However, it is possible that those who were not treated for their burn experience even more extreme chronic outcomes from the burn injury, which would further corroborate the results of this study. Second, this study took place in Pietermaritzburg, an urban area of KZN, excluding patients who reside in more rural and less developed regions. Third, specific data were not collected on interview refusal rates and the reasons. However, the participation rate was over $90 \%$. Lastly, the study sample size $(n=35)$ may reduce generalizability of this qualitative study. 


\section{Conclusions}

The results of this study highlight the lived experiences of caregivers and patients after discharge for a burn injury. The most notable discussions regarded stigma, difficulty accepting self-image, loss of relationships, returning to work, and barriers in receiving long-term aftercare at the hospital outpatient clinic. These patients and caregivers faced wide-ranging and severe difficulties in re-integrating into society. They also shed light on specific areas in which public health practitioners can develop targeted interventions, such as providing options for transportation to the clinic and employment resources. This study suggests specific interventions that are most appropriate to this setting, such as psychosocial support groups integrated with post-burn care, as well as support for other patient and family needs. Future interventions targeting these specific areas should be evaluated in this setting, with important implications for global health policy related to burn and injury prevention.

Author Contributions: Conceptualization, C.A.R., A.R.A., A.D.H. and N.A.; methodology, C.A.R., A.D.H., A.R.A.; formal analysis, C.A.R. and A.D.H.; investigation, C.A.R. and N.A.; data curation, C.A.R. and N.A.; writing-original draft preparation, C.A.R. and A.D.H.; writing-review and editing, C.A.R., A.D.H., A.R.A. and N.A.; data collection supervision, N.A.; funding acquisition, C.A.R. and A.D.H. All authors have read and agreed to the published version of the manuscript.

Funding: This research was funded by the Brown University Global Public Health Program.

Institutional Review Board Statement: This study was accepted by the University of KwazuluNatal's (UKZN) Biomedical Research Ethics Committee (B006/19) and the KZN Department of Health (KZ_201902_014). Brown University and UKZN completed an IRB Authorization Agreement (\#19-25).

Informed Consent Statement: Informed consent was obtained from all subjects involved in the study.

Acknowledgments: We would like to extend our gratitude to the research staff and participants at Edendale Hospital. This would not be possible without the individuals who shared their stories for this. Thank you to our translator, Banele Mpetsheni, for your hard work and dedication on this study project. Thank you to the Brown University Global Health faculty for their guidance.

Conflicts of Interest: The authors declare no conflict of interest.

Appendix A. Adult Semi-Structured Interview Guides

ADULT PATIENT INTERVIEW SCHEDULE

(1) Initial Burn Incident

The purpose of this section is to understand what caused the burn and how quickly they were able to get medical attention.

Question: Tell me about the initial burn incident. For example, describe the situation in which it occurred and what you did immediately after the incident.

Probes:

a. What caused the burn?

b. Describe in your own words what the initial medical treatment was like?

c. Where did you receive this medical treatment?

d. Who was the provider that you saw?

e. Why did you choose to go to that specific place?

f. How did you get there? 


\section{ADULT PATIENT INTERVIEW SCHEDULE}

\section{(2) Follow Up Care}

The purpose of this portion is to ask about barriers to follow up care the patient may be experiencing. Question: At the facility where you received treatment, what did they tell you about follow up care?

Probes:

a. Why do you think that it is important to receive follow up care for scars?

b. What do you think the consequences are of not receiving follow up care for a scar?

c. What are you doing at home to take care of your wounds when they cause pain?

Question: Tell me about your experience returning to the clinic for follow up visits.

Probes:

a. What were the best aspects of your follow up care?

b. How long does it take you to get to the hospital?

c. What barriers do you face in attempting to receive follow up care? (For example, cost, transportation, etc.)

d. What form of transportation do you take to get to clinic and how accessible is that to you?

(3) Current Health Status

The purpose of this portion is to understand how they are recovering and explore why they came back for follow up care.

Question: Please describe your current health status in regard to your burn injury.

Probes:

a. In what ways do you suffer from pain from the burn injury? How does if interfere with your ability to sleep?

b. In what ways do you suffer from pruritus (severe itching)? How does it interfere with your ability to sleep?

c. Please describe any contractures formed that have affected your ability to function normally and partake in physical activity?

d. Do you currently take any medicine for pain or itching? Does it help?

(4) Behavioral Changes

Question: Would you please explain any changes you've noticed in your personality or behavior since the burn?

\section{Probes:}

a. Do you ever experience flashbacks from the burn accident? Please explain.

b. Do you ever have nightmares about the accident? Can you describe these dreams?

c. Do you avoid places or things that remind you of the event? Why?

(5) (If participant is employed) Returning to Work and Life, Stigmatization

The purpose of this section is to understand how the patient was able to integrate into their previous life and what the consequences of the burn are for him/her/they. Additionally, the purpose of this section is to explore any stigmatization the patient may feel in his/her community.

Question: After you left the hospital, how easy or difficult was it for you to return to your normal life? Please discuss what it was like.

Probes:

a. What was the first thing you did after leaving?

b. How did you get home?

c. How much work did you miss due to the burn?

d. Was your workplace understanding of your absence?

e. How would you describe your level of work since the burn?

Question: What role did your family and friends play in your recovery?

Question: Have you ever been treated differently because of your burn injury by peers?

Probes:

a. How has this affected you?

b. What do you think the social stigma is when burn injuries?

c. Did this influence your decision to return and receive follow up care? 


\section{Appendix B. Caregiver Semi-Structured Interview Guides}

\section{CAREGIVER INTERVIEW SCHEDULE}

(1) Initial Burn Incident

The purpose of this section is to understand what caused the burn and how quickly they were able to get medical attention.

Question: Tell me about the initial burn incident. For example, describe the situation in which it occurred and what you did immediately after the incident.

Probes:

a. What caused the burn?

b. Describe in your own words what the initial medical treatment was like?

c. Where did you receive this medical treatment?

d. Who was the provider that you saw?

e. Why did you choose to gapo to that specific place?

f. How did you get there?

(2) Follow Up Care

The purpose of this portion is to ask about barriers to follow up care the patient may be experiencing. Question: At the facility where you received treatment, what did they tell you and your child about follow up care?

Probes:

a. Why do you think that it is important to receive follow up care for scars?

b. What do you think the consequences are of not receiving follow up care for a scar?

c. What are you doing at home to take care of your wounds when they cause pain?

Question: Tell me about your child's experience returning to the clinic for follow up visits. Probes:

a. How long does it take you to get to the hospital?

b. What barriers/facilitators does your child face in attempting to receive follow up care?

c. What form of transportation do you take to get to clinic and how accessible is that to you and your child?

(3) Current Health Status

The purpose of this portion is to understand how they are recovering and explore why they came back for follow up care.

Question: Please describe your child's current health status in regard to your burn injury.

Probes:

a. In what ways does your child experience pain from the burn injury?

b. How does if interfere with his/her/their ability to sleep?

c. In what ways does your child experience pruritus (severe itching)?

d. How does it interfere with his/her/their ability to sleep

e. Please describe any contractures formed that have affected your child's ability to function normally and partake in physical activity?

f. Does he/she/they currently take any medicine for pain or itching?

g. Do you think it helps?

(4) Behavioral Changes

Question: Would you please explain any changes you've noticed in your child's personality or behavior since the burn?

Probes:

a. Does he/she/they ever experience flashbacks from the burn accident? Please explain.

b. Does he/she/they ever have nightmares about the accident? Can you please describe these dreams?

c. Does he/she/they avoid places or things that remind you of the event? 


\section{CAREGIVER INTERVIEW SCHEDULE}

(5) Returning to School and Life, Stigmatization

The purpose of this section is to understand how the patient was able to reintegrate into their previous life and what the consequences of the burn are for him/her/they. Additionally, the purpose of this section is to explore any stigmatization the patient may feel in his/her/their community.

Question: After you left the hospital, how easy or difficult was it for your child to return to his/her life? Please discuss what it was like.

Probes:

a. What was the first thing you did after leaving?

b. How did your child get home?

c. How much school was missed due to the burn? Does he/she/they go to school?

d. How would you describe his/her/their level of work since the burn?

Question: What role did your family and friends play in your child's recovery?

\section{References}

1. World Health Organization. A WHO Plan for Burn Prevention and Care; World Health Organization: Geneva, Switzerland, 2008. Available online: https:/ / apps.who.int/iris/handle/10665/97852 (accessed on 24 January 2021).

2. World Health Organization. Injuries and Violence: The Facts; World Health Organization: Geneva, Switzerland, 2014. Available online: https:/ / apps.who.int/iris/handle/10665/149798 (accessed on 24 January 2021).

3. Barrett, L.W.; Fear, V.S.; Waithman, J.C.; Wood, F.M.; Fear, M.W. Understanding acute burn injury as a chronic disease. Burn. Trauma 2019, 7, 23. [CrossRef] [PubMed]

4. McLean, L.; Chen, R.; Kwiet, J.; Streimer, J.; Vandervord, J.; Kornhaber, R. A clinical update on posttraumatic stress disorder in burn injury survivors. Australas. Psychiatry 2017, 25, 348-350. [CrossRef] [PubMed]

5. Tredget, E.E.; Shupp, J.W.; Schneider, J.C. Scar management following burn injury. J. Burn Care Res. 2017, 38, 146-147. [CrossRef] [PubMed]

6. Knudson-Cooper, M.; Thomas, C. Psychosocial care of the severely burned child. In Burns in Children: Pediatric Burn Management; Carvajal, H., Parks, D., Eds.; Year Book Medical Publishers: Chicago, IL, USA, 1988; pp. 345-362.

7. MacLeod, R.; Shepherd, L.; Thompson, A.R. Posttraumatic stress symptomatology and appearance distress following burn injury: An interpretative phenomenological analysis. Health Psychol. 2016, 35, 1197-1204. [CrossRef] [PubMed]

8. Palmu, R.; Suominen, K.; Vuola, J.; Isometsä, E. Mental disorders after burn injury: A prospective study. Burns 2011, 37, 601-609. [CrossRef] [PubMed]

9. Blakeney, P. School reintegration. J. Burn Care Rehabil. 1995, 16 Pt 1, 180-187. [CrossRef]

10. Esselman, P.C.; Askay, S.W.; Carrougher, G.J.; Lezotte, D.C.; Holavanahalli, R.K.; Magyar-Russell, G.; Fauerbach, J.A.; Engrav, L.H. Barriers to Return to Work After Burn Injuries. Arch. Phys. Med. Rehabil. 2007, 88 (Suppl. 2), S50-S56. [CrossRef] [PubMed]

11. Stoddard, F.J. Body Image Development in the Burned Child. J. Am. Acad. Child Psychiatry 1982, 21, 502-507. [CrossRef]

12. Peck, M.D. Epidemiology of burns throughout the world. Part I: Distribution and risk factors. Burns 2011, 37, 1087-1100. [CrossRef]

13. Blakeney, P.; Meyer, W.; Moore, P.; Broemeling, L.; Hunt, R.; Robson, M.; Herndon, D. Social competence and behavioral problems of pediatric survivors of burns. J. Burn Care Rehabil. 1993, 14, 65-72. [CrossRef] [PubMed]

14. Van Niekerk, A.; Laubscher, R.; Laflamme, L. Demographic and circumstantial accounts of burn mortality in Cape Town, South Africa, 2001-2004: An observational register based study. BMC Public Health 2009, 9, 374. [CrossRef]

15. Van Niekerk, A.; Rode, H.; Laflamme, L. Incidence and patterns of childhood burn injuries in the Western Cape, South Africa. Burns 2004, 30, 341-347. [CrossRef] [PubMed]

16. Scheven, D.; Barker, P.; Govindasamy, J. Burns in rural Kwa-Zulu Natal: Epidemiology and the need for community health education. Burns 2012, 38, 1224-1230. [CrossRef] [PubMed]

17. Allorto, N.; Oosthuizen, G.; Clarke, D.; Muckart, D. The spectrum and outcome of burns at a regional hospital in South Africa. Burns 2009, 35, 1004-1008. [CrossRef] [PubMed]

18. Kornhaber, R.A.; de Jong, A.; McLean, L. Rigorous, robust and systematic: Qualitative research and its contribution to burn care. An integrative review. Burns 2015, 41, 1619-1626. [CrossRef] [PubMed]

19. Allorto, N.L.; Zoepke, S.; Clarke, D.L.; Rode, H. Burn surgeons in South Africa: A rare species. S. Afr. Med. J. 2016, 106, 186. [CrossRef] [PubMed]

20. Allorto, N.L.; Clarke, D.L. Merits and challenges in the development of a dedicated burn service at a regional hospital in South Africa. Burns 2015, 41, 454-461. [CrossRef] [PubMed]

21. QSR International Pty Ltd. NVivo (Version 12). 2018. Available online: https://www.qsrinternational.com/nvivo-qualitativedata-analysis-software/home (accessed on 24 January 2021). 
22. Ritchie, J.; Lewis, J.; Nicholls, C.M.; Ormston, R. Qualitative Research Practice: A Guide for Social Science Students and Researchers; SAGE: Los Angeles, CA, USA, 2014.

23. Tolley, E.E.; Ulin, P.R.; Mack, N.; Robinson, E.T.; Succop, S.M. Qualitative Methods in Public Health: A Field Guide for Applied Research, 2nd ed.; Wiley: San Francisco, CA, USA, 2016.

24. Smolle, C.; Cambiaso-Daniel, J.; Forbes, A.A.; Wurzer, P.; Hundeshagen, G.; Branski, L.K.; Huss, F.; Kamolz, L.-P. Recent trends in burn epidemiology worldwide: A systematic review. Burns 2017, 43, 249-257. [CrossRef]

25. Mock, C.N.; Smith, K.R.; Kobusingye, O.; Nugent, R.; Abdalla, S.; Ahuja, R.B.; Apramian, S.S.; Bachani, A.M.; Bellis, M.A.; Butchart, A.; et al. Injury Prevention and Environmental Health: Key Messages from Disease Control Priorities. In Disease Control Priorities, Volume 7: Injury Prevention and Environmental Health, 3rd ed.; The International Bank for Reconstruction and Development/The World Bank: Washington, DC, USA, 2017.

26. Mock, C.N.; Gloyd, S.; Adjei, S.; Acheampong, F.; Gish, O. Economic consequences of injury and resulting family coping strategies in Ghana. Accid. Anal. Prev. 2003, 35, 81-90. [CrossRef]

27. Kornhaber, R.; Wilson, A.; Abu-Qamar, M.Z.; McLean, L. Adult burn survivors' personal experiences of rehabilitation: An integrative review. Burns 2014, 40,17-29. [CrossRef]

28. Vlastelica, M. Psycholo gical support to burn patients. Acta Med. Croat. 2014, 68 (Suppl. 1), $39-49$.

29. Dang, R.; Wang, Y.; Li, N.; He, T.; Shi, M.; Liang, Y.; Zhu, C.; Qi, Y.Z.Z.; Hu, D. Effects of group psychological counseling on self-confidence and social adaptation of burn patients. Chin. J. Burns. 2014, 30, 487-490.

30. Grieve, B.; Shapiro, G.; Wibbenmeyer, L.; Acton, A.; Lee, A.; Marino, M.; Jette, A.; Schneider, J.C.; Kazis, L.E.; Ryan, C.M.; et al. Long-Term Social Reintegration Outcomes for Burn Survivors with and without Peer Support Attendance: A Life Impact Burn Recovery Evaluation (LIBRE) Study. Arch. Phys. Med. Rehabil. 2020, 101, S92-S98. [CrossRef] [PubMed]

31. Barnett, B.S.; Mulenga, M.; Kiser, M.M.; Charles, A.G. Qualitative analysis of a psychological supportive counseling group for burn survivors and families in Malawi. Burns 2017, 43, 602-607. [CrossRef] [PubMed]

32. Frenkel, L. A support group for parents of burned children: A South African Children's Hospital Burns Unit. Burns 2008, 34, 565-569. [CrossRef] [PubMed]

33. Serghiou, M.; Niszczak, J.; Parry, I.; Li-Tsang, C.W.; Kerckhove, E.V.D.; Smailes, S.; Edgar, D. One world one burn rehabilitation standard. Burns 2016, 42, 1047-1058. [CrossRef]

34. Rencken, C.A.; Allorto, N.; Harrison, A.D.; McGarvey, S.T.; Aluisio, A.R. Factors associated with adherence to follow-up care after burn injuries. Burns 2021, 47, 240-248. [CrossRef]

35. Starbird, L.E.; DiMaina, C.; Sun, C.-A.; Han, H.-R. A Systematic Review of Interventions to Minimize Transportation Barriers Among People with Chronic Diseases. J. Community Health 2019, 44, 400-411. [CrossRef] [PubMed] 